\title{
DISCRETE MATHEMATICS INTO K-11 AND K-12 GRADE EDUCATION
}

\author{
Mr. Balaji. $\mathrm{N}^{1}$, and Dr. Karthik Pai B $\mathrm{H}^{2}$, \\ ${ }^{1,2}$ Department of Information Science and Engineering, \\ ${ }^{1,2}$ NMAM Institute of Technology, Nitte, Karakala - Taluk, Udupi, Karnataka, INDIA. \\ Email:림ai.hiriyur@gmail.com, ${ }^{2}$ karthikpaibh@gmail.com
}

D.O.I-10.51201/JUSST/21/05150

http://doi.org/10.51201/JUSST/21/05150

\begin{abstract}
Discrete mathematics is one of the significant part of K-11 and K-12 grade college classrooms. In this contribution, we discuss the usefulness of basic elementary, some of the intermediate discrete mathematics for K-11 and K-12 grade colleges. Then we formulate the targets and objectives of this education study. We introduced the discrete mathematics topics such as set theory and their representation, relations, functions, mathematical induction and proof techniques, counting and its underlying principle, probability and its theory and mathematical reasoning. Core of this contribution is proof techniques, counting and mathematical reasoning. Since all these three concepts of discrete mathematics is strongly connected and creates greater impact on students. Moreover, it is potentially useful in their life also out of the college study. We explain the importance, applications in computer science and the comments regarding introduction of such topics in discrete mathematics. Last part of this article provides the theoretical knowledge and practical usability will strengthen the made them understand easily.
\end{abstract}

\section{Keywords: K-11, K-12 grade, Proof Techniques, Combinatorics, Mathematical Reasoning.}

\section{Introduction}

This article describes the K-11 and K-12 classrooms that I have observed and/or taught during the year 2018-2019 college year. Critics have claimed that mathematics taught in K-11 and K-12 is nothing more than memorizing the facts rather than computing the method of solving the given problem with a known concept of study. Topic of study which includes discrete mathematics are Set Theory, Relations and Functions, Principles of Mathematical Induction, Permutation and Combinations, Mathematical Reasoning, Probability and some study about Matrices and Determinants. For the past 7 to 8 years, I have been involved with professional development work for K-11 and K-12 teachers of mathematics, including the active participation in the discrete mathematics. This experience and with my background in mathematics education, has provided many opportunities to collaborate with K-11 and K-12 teachers who are representing and implementing discrete mathematics in their classrooms. Based on these background study and experiences, I believe that it is important to incorporate the discrete mathematics into existing curriculum for the effective teaching and learning process in K-11 and K-12 college classrooms.

Discrete Mathematics course is a core part of computer / information science \& technology and it facilitates the study of applications in the field of computer science, especially in the areas of data structures, the theory of computer languages and the analysis of algorithms. In addition, this course also provides students with understanding of applications in engineering and the physical and life sciences, as well as in statistics and the social sciences.

To introduce the student at the high-school level, if not earlier, to the topics and techniques of discrete methods and combinatorial reasoning. Whenever the structures from abstract algebra are required, only the basic theory needed for the application development. Further, the solution of the some applications contribute to the iterative procedures that lead to specific algorithms. The algorithmic approach and solution for the problems is fundamental in discrete mathematics. 
From the traditional coverage on calculus and differential equations, students has to develop the mathematical maturity through the study of an area that is so different. For example, to establish results by counting a certain collection of objects provides the combinatorial identities; and also provides a novel proof techniques.

\section{Discrete Mathematics Official Curriculum in K-11 and K-12 College Classrooms}

In this section we discuss syllabi in K-11 and K-12 college classrooms in India. In the first we briefly visit the K-11 and K-12 syllabi, then we look into the recent situation on K-11 and K-12 regarding discrete mathematics. Then we discuss the reasons why to teach about it as well as specific educational targets.

Here we revisit the basic concepts about K-11 college classrooms which comprises the topics such as Set Theory, Relations and Functions, Principles of Mathematical Induction, Permutation and Combination, Mathematical Reasoning and Probability. At first we shall make clear that basic concepts of discrete mathematics in K-11 college classrooms plays a vital role in the field of computer science and applications.

Underlying the mathematics we study in algebra, geometry, combinatorics, probability, and almost every other area of contemporary mathematics is the notion of a set. Much of the discrete structures is devoted to the study of discrete structures, used to represent discrete objects. Many important discrete structures are built using sets, which are distinct collection of objects. In subsequent tables [1 to 6] gives the detailed description and significance of the same is represented.

\section{Table 1: Detailed Syllabi in Set Theory}

\begin{tabular}{|c|c|l|}
\hline$\#$ & Topic of Study & \multicolumn{1}{c|}{ Content Description } \\
\hline 1 & $\begin{array}{c}\text { Sets and their } \\
\text { Representation }\end{array}$ & $\begin{array}{l}\text { Comprises the basic definition of set, notations used to represent the set, } \\
\text { methods of representing any set (both roster and rule method), and few } \\
\text { examples on the same. }\end{array}$ \\
\hline 2 & Types of Sets & $\begin{array}{l}\text { Based on the representations we drafted few distinguished sets namely empty } \\
\text { set, finite \& infinite set, equal sets and Universal set. The major property of } \\
\text { set is subset property which gives especially on real numbers known as } \\
\text { Power set. This property plays a very significant role in computer science } \\
\text { and application field. }\end{array}$ \\
\hline 3 & Operations on Set & $\begin{array}{l}\text { Union, Intersection, Difference of sets, Complement of a set which is a } \\
\text { unique property of set theory. With this backdrop, we defined the laws of set } \\
\text { theory, properties on complement sets. We found some simple practical } \\
\text { problems on union and intersection of two sets. }\end{array}$ \\
\hline 4 & Venn Diagrams & $\begin{array}{l}\text { Distinguished operations of two sets, complement of a set is represented } \\
\text { using a special kind of diagram known as Venn diagrams. It is a simple and } \\
\text { powerful tool to represent any set operations. }\end{array}$ \\
\hline
\end{tabular}

Table 2: Detailed Syllabi in Relations and Functions

\begin{tabular}{|c|c|l|}
\hline$\#$ & Topic of Study & \multicolumn{1}{c|}{ Content Description } \\
\hline 1 & $\begin{array}{c}\text { Cartesian Product } \\
\text { of Sets }\end{array}$ & $\begin{array}{l}\text { An ordered pairs, cartesian products, number of elements in the cartesian } \\
\text { product of two sets which leads to the concept of counting (enumeration). }\end{array}$ \\
\hline 2 & Relations & $\begin{array}{l}\text { Defining the relation with the concept of cartesian product, which leads to a } \\
\text { very well-known concept called Graphs (directed graphs) and its } \\
\text { relationships are represented using edges. These graphs are directed graphs } \\
\text { which in turn shows that how the relationships have been defined and from } \\
\text { which node to which how these relationships are explored. In discrete }\end{array}$ \\
\hline
\end{tabular}




\begin{tabular}{|c|c|l|}
\hline & & $\begin{array}{l}\text { mathematics formally called it as Domain and Co-Domain and we are trying } \\
\text { to enumerating these with the help of counting. }\end{array}$ \\
\hline 3 & Types of Relations & $\begin{array}{l}\text { Reflexive, Symmetric, Transitive, Empty, Universal and Equivalence } \\
\text { relations followed by examples and problems. These different types of } \\
\text { relations explores the different types of properties in the graph theory and we } \\
\text { extensively used in the different applications of computer science. }\end{array}$ \\
\hline 4 & Functions & $\begin{array}{l}\text { Function as a special kind of relation from one set to another. Pictorial } \\
\text { representation of a function, domain, co-domain and range of a function. Real } \\
\text { valued function of the real variable, domain and range of constant, identity, } \\
\text { polynomial rational, modulus, signum and greatest integer functions with } \\
\text { their graphs. }\end{array}$ \\
\hline 5 & Types of Functions & $\begin{array}{l}\text { One to one and onto functions, inverse of a function composite functions, } \\
\text { mentioning their properties only, examples and problems. }\end{array}$ \\
\hline 6 & Binary Operations & \begin{tabular}{l} 
Associative, Commutative, Identity, Inverse with examples. \\
\hline
\end{tabular}
\end{tabular}

Table 3: Detailed Syllabi in Principle of Mathematical Induction

\begin{tabular}{|c|c|l|}
\hline$\#$ & Topic of Study & \multicolumn{1}{c|}{ Content Description } \\
\hline 1 & $\begin{array}{c}\text { Principle of } \\
\text { Mathematical } \\
\text { Induction }\end{array}$ & $\begin{array}{l}\text { Process of the proof by induction, motivating the application of the method } \\
\text { by looking at natural numbers as the least inductive subset of real numbers. } \\
\text { The principle of mathematical induction and simple problems based on } \\
\text { summation only. } \\
\text { This ensures the various proofs in computer science and its applications and } \\
\text { this plays a very significant role in various real time problems in the society. }\end{array}$ \\
\hline
\end{tabular}

Table 4: Detailed Syllabi in Permutation and Combinations

\begin{tabular}{|c|c|l|}
\hline$\#$ & Topic of Study & \multicolumn{1}{|c|}{ Content Description } \\
\hline 1 & $\begin{array}{c}\text { Counting and Its } \\
\text { Fundamental } \\
\text { Principle }\end{array}$ & $\begin{array}{l}\text { Motivation for Counting and Paper Folding Example, Rubik's Cube } \\
\text { Example, Approaching a Factorial Example, Counting in Computer Science. }\end{array}$ \\
\hline 2 & Permutation & $\begin{array}{l}\text { Defining permutation with various examples, derivation formula for } \\
\text { permutation, permutation when all the objects are not distinct with examples. }\end{array}$ \\
\hline 3 & Combinations & $\begin{array}{l}\text { Defining combination with various examples, derivation formula for } \\
\text { combination, combination with repetitions and its proofs, example problems. }\end{array}$ \\
\hline
\end{tabular}

Table 5: Detailed Syllabi for Probability

\begin{tabular}{|c|c|l|}
\hline$\#$ & Topic of Study & \multicolumn{1}{c|}{ Content Description } \\
\hline 1 & Probability & $\begin{array}{l}\text { Random experiments, outcomes, sample spaces (set representation). Events } \\
- \text { occurrence of events, 'not', 'and' \& 'or' events, exhaustive events, mutually } \\
\text { exclusive events. Axiomatic (set theoretic) probability, connections with the } \\
\text { theories of earlier classes. Probability of an event, probability of 'not', 'and', } \\
\& \text { 'or' events, example problems. }\end{array}$ \\
\hline 2 & $\begin{array}{l}\text { Conditional } \\
\text { Probability }\end{array}$ & $\begin{array}{l}\text { Definition, illustration with an example, properties and problems. } \\
\text { Multiplication Theorem, Independent events, Baye's Theorem and its proof, } \\
\text { Theorem of total probability and illustration with various problems. }\end{array}$ \\
\hline
\end{tabular}




\begin{tabular}{|c|c|l|}
\hline 3 & $\begin{array}{c}\text { Probability } \\
\text { Distribution on a } \\
\text { Random Variable }\end{array}$ & $\begin{array}{l}\text { Generating a random variable with example illustration, definition of a } \\
\text { random variable, distribution on a random variable, Mean and Variance of a } \\
\text { random variable. }\end{array}$ \\
\hline 4 & $\begin{array}{c}\text { Bernoulli's Trails } \\
\text { and Binomial } \\
\text { Distribution }\end{array}$ & $\begin{array}{c}\text { Definition of Bernoulli's Trail \& Binomial Theorem, Condition for Binomial } \\
\text { distribution and simple problems. }\end{array}$ \\
\hline
\end{tabular}

Table 6: Detailed Syllabi of Mathematical Reasoning

\begin{tabular}{|c|c|l|}
\hline$\#$ & Topic of Study & \multicolumn{1}{c|}{ Content Description } \\
\hline 1 & $\begin{array}{c}\text { Mathematical } \\
\text { Logic }\end{array}$ & $\begin{array}{l}\text { Motivational examples, Introduction to statements, propositions and its } \\
\text { illustration examples. }\end{array}$ \\
\hline 2 & $\begin{array}{c}\text { Logical } \\
\text { Connectives }\end{array}$ & $\begin{array}{l}\text { Connectives such as 'AND', 'OR', 'NOT', 'Conditional' and 'Bi-conditional' } \\
\text { with their truth tables and examples. These connectives are used to combine } \\
\text { one or more propositions together to assert some meaning. }\end{array}$ \\
\hline 3 & Quantifiers & $\begin{array}{l}\text { An expression that indicates the scope of a term to which it is attached. } \\
\text { Concept of converse, inverse and contra-positive statements are introduced } \\
\text { and represented using the basic connectives. These are used to find the } \\
\text { validity of the compound proposition whether it is true or false for all the } \\
\text { possible truth values for the given compound statement. }\end{array}$ \\
\hline 4 & Proof Method & $\begin{array}{l}\text { A new method of proving methodology is introduced named as Proof by } \\
\text { Contradiction. This methodology will provide the unique way of finding the } \\
\text { validity of compound statements. }\end{array}$ \\
\hline
\end{tabular}

\section{Reason for Including Discrete Mathematics Official Curriculum into K-11 and K-12 Education}

We have described the significant role of discrete mathematics in K-11 and K-12 college classrooms. Considering how frequent they are, they stand as one of the reasons why to include discrete mathematics into K-11 and K-12 education programmes. Discrete mathematics provides a new way of work with, different from other classical approaches from college mathematics. This provide poor skilled student with a new chance to catch up in mathematics. Even though the way of representing the topics differ and it may be mostly about proving, asserting, and checking the validity and others. The same idea works with various computer science related problems such as data structures, algorithms, and graph theory. In various context we are using for solving complex problems in the field of network and security which is a very important aspect of any individual machine.

It is important to notice that the basics are very intuitive, discrete mathematics provides advanced topics of various difficulty. Most of them have their important applications as well as theoretical impact. For an instance, we have taken the concept of set theory, concentrates on finite sets. Very little is said about infinite sets. In some problems or ways these two sets have very different properties. For example, a finite set never has the same cardinality as any of its proper subsets. Where, the infinite sets do contain proper subsets having the same cardinality as the full set. The logic section are to be comfortable with the manner in which the proofs are completed. The main focus in the logic sections are to become familiar with the notation and major concepts (proposition, basic connectives, truth tables, quantifiers, etc.) and to observe the similarity between the way of proof used in the section about sets and the method of proof that uses a sequence of logical equivalences. It is also important you understand the process of negating a quantified statement. Concluded, the reasons for teaching discrete mathematics is in their practical usefulness as well as in their challenging theoretical background. 


\section{Education Targets}

Here we illustrate shortly the main targets specific for discrete mathematics education, as we designed so far. To begin with, student shall recognize the proper situation to apply the discrete mathematics concepts such as mathematical induction with proof techniques, counting and it fundamental principle, probability theory, mathematical reasoning and etc. The more difficult goal is to motivate you start the process of efficiently produce the proofs. Proofs are essential and core feature of future mathematical courses and this provides not only the truth of the assertions but also the best proof with a truth value.

Counting concept introduces the basic collection of counting techniques with few motivational examples such as paper folding example, Rubik's cube problem etc. This provides, count visually distinguishable patterns (Binomial Theorem) for collection of objects with identifiable types of objects, each with several copies are available. Counting the number of distinct elements in a union of possibly non-disjoint sets (inclusion-exclusion formula).

Probability theory conceptualize the foundational explanations (event, sample space, independence). Methods of determining the probabilities of events are introduced and the notion of equally likely outcomes are defined. The notion of a random variable is to create a variable whose value is determined by the outcome of a random experiment. Probability distribution described for a particular pattern and a collection of conditional probabilities into a different set of conditional probabilities (Bayes's Theorem).

On higher level, they should be aware of some meta-knowledge and heuristics, and be able to use them appropriately. They should be aware that there are many approaches to achieve the same goal but using the appropriate method of solving the problem and reach the desired result. Influenced by all the examples in discrete mathematics concepts, students shall know it is good to work systematically and in phases, virtually every time when it is possible. Educational targets describes above includes both practical usability and theoretical knowledge. These two aspect shall strength each other systematically, where every student of $\mathrm{K}-11$ and K-12 grade classes efficiently.

\section{Conclusion}

In this article, we summarized the detailed curriculum of K-11 and K-12 college classrooms. We have examined the current situation, how teachers are conducting the different topics of study in discrete mathematics and its applications perspective. Based on the curricula designed in table 1 to 6 considered is important and what should be the benefits of including it. Graphs are very helpful tool for better understanding of the concept of relations and checking their different properties through the same. This is the way we want K-11 and K-12 grade college students to see the concept of relations. Various problems in computer science and applications are approached with the help of relation followed by their properties. Likewise, the topic of study in table 1 to 6 has its own significant role in various computer science and applications filed. K-11 and K-12 grade college students already using this intuitively. Yet, they are not aware of any special knowledge and applications behind. We believe that showing it to them would improve their studies. They would able to nurture themselves and use their discrete mathematics related knowledge and skills in new areas.

\section{References}

[1] D. Lessner, “Graph Theory in High School Education”, in Semantic Scholar, 2010.

[2] Zackery Reed and Elise Lockwood, “Generalizing in Combinatorics through Categorization”, in Special Interest Group of the MAA, in 2018.

[3] Valerie A. DeBellis, "Discrete Mathematics in K-2 Classrooms", in DIMACS in Discrete Mathematics and Theoretical Computer Science, Volume - 36, 1997. 
[4] Tom Coenen, Frits Hof and Nellie Verhoef, "Combiatorial Reasoning To Solve Problems", in $13^{\text {th }}$ International Congress on Mathematical Education, Hamburg, July 2016.

[5] Valerie A. DeBellis and Joseph G. Rosentein, "Discrete Mathematics in Primary and Secondary School in the United States", in Analyses: Zentralblatt fur Didaktik der Mathematik, June 2004.

[6] Ralph P Grimaldi, "Discrete and Combinatorial Mathematics", $5^{\text {th }}$ Edition, by Pearson Publication, 1999.

[7] Kenneth H. Rosen, "Discrete Mathematics and its Applications", $6^{\text {th }}$ Edition, by McGraw Hill International Edition, 2007.

[8] Eric Gosset, "Discrete Mathematics with Proof", $2^{\text {nd }}$ Edition, by John Wiley Publication, 2014. 